\title{
A dádiva e 0 terceiro paradigma nas ciências sociais: as contribuicões antiutilitaristas de Alain Caillé
}

PAULO HENRIQUE MARTINS*

\section{Resumo}

A palavra dádiva tem recepção ambivalente nas ciências sociais, no Brasil, na medida em que sugere, numa leitura superficial, um entendimento religioso e gratuito da doação. Mas a dádiva é um sistema teórico relacional que revela a complexidade das relações sociais no passado e no presente. Este reconhecimento levou Alain Caillé a propor a dádiva como um terceiro paradigma que seria mais complexo que aqueles marcados pelas tradições do individualismo e do holismo. A análise das contribuições deste autor é fundamental para se entender as tendências contemporâneas do debate que é crucial no desenvolvimento da escola francesa de sociologia fundada por Émile Durkheim.

Palavras-chave: Dádiva. Teoria Social. Alain Caillé.

* Universidade Federal de Pernambuco, Brasil 


\title{
The gift and the third paradigm in the social sciences: the anti-utilitarian contributions of Alain Caillé
}

\begin{abstract}
The word "gift" has an ambivalent reception in the social sciences in Brazil, because through a superficial reading it suggests a gratuitous and religious understanding of the donation. But the gift comprises a relational theoretical system, which reveals the complexity of social relationships in the past and the present. This recognition led Alain Caillé to propose the gift as a third paradigm, which would be more complex than those marked by the traditions of individualism and holism. The analysis of the contributions of this author is fundamental to understand the contemporary trends of the debate that is crucial in the development of the French school of sociology founded by Émile Durkheim.
\end{abstract}

Keywords: Gift. Social theory. Alain Caillé.

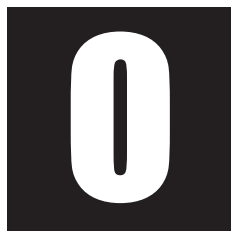

paradigma da dádiva, sistematizado por Alain Caillé1, constitui uma das mais importantes contribuições contemporâneas da Escola Francesa de Sociologia, na medida em que atualiza a crítica moral ao utilitarismo da sociedade moderna, a qual está presente, inicialmente, na obra de Émile Durkheim (2004) e que foi continuada por Marcel Mauss (2003). A crítica do utilitarismo é fundamental para esta Escola.

Já no segundo prefácio da obra Da divisão Social do Trabalho, Durkheim chama a atenção para o estado de anomia jurídica e moral da

\footnotetext{
${ }^{1}$ Alain Caillé é Docteur d'Etat em Ciências Econômicas e Sociologia, tendo sido o primeiro assistente de Claude Lefort quando este ainda era professor na Universidade de Caen (França). Em 1980, juntamente com amigos e representantes de diversas disciplinas fundou o Bulletin du M.A.U.S.S., que propunha uma crítica multidimensional e multidisciplinar da axiomática do interesse. No final dos anos 80, este boletim se transformou na Revue du M.A.U.S.S., que existe até hoje, tendo papel importante na crítica antiutilitarista e antineoliberal.
} 
vida econômica. Para ele, a autonomização das funções econômicas era assunto grave, pois contribuiria para ampliar o falso antagonismo entre a autoridade da regra e a liberdade do indivíduo. Segundo Durkheim, a falsidade dessa tese estaria no fato de que a liberdade justa que a sociedade deveria respeitar, deveria ser, ela própria, fruto de uma regulamentação (Durkheim, 2004, pp. vi-viii). Vemos, aqui, que já no século XIX os avanços das ideias liberais e utilitaristas preocupavam muito ao fundador da sociologia francesa. Esta mesma preocupação antiutilitarista está presente em Mauss quando afirma, nos anos 20 do século passado, que uma parte considerável de nossa moral e da nossa vida permanece estacionada nessa atmosfera de dádiva, obrigação e liberdade e que "felizmente, nem tudo ainda é classificado exclusivamente em termos de compra e venda" (Mauss, 2003, pp. 294). Assim, tanto a ideia de regulamentação, em Durkheim, como dos contratos de obrigação, em Mauss, respondiam ao desafio de promoção de uma moral coletiva justa para a vida social e que não fosse absorvida pela economia utilitarista.

A obra de Alain Caillé constitui, logo, uma contribuição fundamental para se entender o novo ciclo de avanço crítico antiutilitarista da Escola Francesa de Sociologia no atual contexto de hegemonia das teses neoliberais. Esse programa se inicia com a fundação do Bulletin du M.A.U.S.S. (Mouvement AntiUtilitariste dans les Sciences Sociales), em 1980, e avança com a série de reflexões sobre a dádiva que o autor inaugura a partir do final desta mesma década de 80 . Ou seja, para atualizar a crítica à axiomática do interesse e promover os fundamentos de uma moral de solidariedade coletiva que possa regulamentar as tendências de expansão do egoísmo na contemporaneidade, o autor entende ser necessário aprofundar os estudos sobre a dádiva/dom. Em diferentes textos, mas particularmente em Antropologia do dom: o terceiro paradigma (2002a), Caillé propõe haver na mais conhecida obra de Mauss - Ensaio sobre 
a dádiva: Forma e razão da troca nas sociedades arcaicas (Mauss, 2003) - uma virada paradigmática fundamental para as ciências sociais². Nesse sentido, ele amplia o legado original oferecido por Durkheim e Mauss para a fundação de uma sociologia moral e simbólica que continua de grande atualidade (Martins; Pessoa Guerra, 2013).

No desenvolvimento do seu raciocínio e, particularmente no acima citado Antropologia do dom: o terceiro paradigma, Caillé (2002a) sugere três proposições básicas, que apenas na aparência são conflitantes, como iremos observar. Na primeira, ele propõe ser a dádiva um terceiro paradigma. Essa condição de terceiro se justificaria, em princípio, pelo fato desta não ter o mesmo prestígio das duas teses hegemônicas nas ciências sociais na modernidade ocidental, as quais espelham os dilemas clássicos das ciências sociais entre sociedade e individuo - que alguns denominam de holismo e individualismo (quando pensamos na escola francesa) e outros, de agência e estrutura (quando pensamos na escola anglo-saxônica). Assim, ao lado de teses que valorizam a totalidade e o individualismo (primeiro e segundo paradigmas) teríamos a dádiva (terceiro paradigma).

\footnotetext{
${ }^{2} \mathrm{O}$ dom ou a dádiva, como se sabe, trata da presença de uma obrigação social forjada em três movimentos - a doação, a recepção e a retribuição - que existiria, segundo Mauss, em todas as sociedades tradicionais e modernas. A universalidade do dom, explica o autor, é a razão fundamental para a existência das alianças sociais geradoras da vida em comunidade promovendo rituais de confiança, amizade e solidariedade moral. A dádiva emerge nos estudos de Mauss, quando ele se debruça sobre as etnografias das sociedades tradicionais para formular a seguinte indagação: Qual a regra de direito e de interesse que, nas sociedades de tipo atrasado ou arcaico, faz com que o presente recebido seja obrigatoriamente retribuído? Que força existe na coisa dada que faz com que o donatário o retribua? (Mauss, 2003, p. 188). Esta pergunta o leva a concluir que nessas sociedades tradicionais há uma obrigação de prestações entre os membros, a qual permanece até os nossos dias e que ele chama de dádiva. Para ele, esse sistema de prestações, ao mesmo tempo voluntárias e obrigatórias, constitui um rochedo fundamental relacionado à constatação de que o ser humano é essencialmente social, o que enfatiza seu interesse em um entendimento relacional da vida capaz de romper com as estruturas dicotômicas: "...de uma ponta à outra da evolução humana não há duas sabedorias. Que adotemos, então, como princípio de nossa vida o que sempre foi um princípio e sempre o será: sair de si, dar, de maneira livre e obrigatória; não há risco de nos enganarmos" (Mauss, 2003, p. 301).
} 
Pela segunda proposição de Caillé, a dádiva é entendida como um paradigma primordial, o que a reposiciona não como terceiro, mas como primeiro paradigma. A ideia básica, aqui, é que a dádiva constitui um sistema de ação presente em todas as sociedades, modernas e tradicionais, e não somente nas modernas sociedades ocidentais como são os casos dos dois primeiros paradigmas. A dádiva existiria nas sociedades arcaicas antes mesmo das presenças do que se denominam lógicas do mercado ou do estado, aparecendo como o fundamento moral primeiro do pacto social $^{3}$. Aqui se abre importante especulação teórica sobre o universalismo do dom, como iremos ver, na medida em que, estando presente em todas as comunidades humanas, não seria apenas um produto cultural historicamente datado, mas uma condição ontológica da vida em sociedade.

Na terceira proposição Caillé sustenta que a dádiva é um antiparadigma. Isso deve ser entendido não no sentido de que ela seja a negação formal da ideia de paradigma (o que geraria uma contradição com o que foi afirmado anteriormente), mas de problematizar as definições correntes de paradigma científico na modernidade. A ideia de antiparadigma, aqui, pode ser entendida tanto no sentido de que ela se opõe formalmente aos paradigmas dominantes como, igualmente, pelo fato de não aparecer necessariamente como um paradigma científico, mas como uma ontologia, como uma possibilidade explicativa pré-paradigmática. Nesse último caso, a dádiva é apenas uma intenção, um estado de latência que, ao ser acionado na invenção do social, tanto pode gerar pacto de solidariedade como, no sentido contrário, sua desorganização. Quem dá amor, recebe a vida; quem dá a dor, recebe a morte. Neste último caso, ela pode, simplesmente, destruir os paradigmas convencionados.

${ }^{3}$ Este assunto é tratado claramente por Marcel Mauss no seu "Ensaio sobre a dádiva. Forma e razão da troca nas sociedades arcaicas" In: Sociologia e antropologia. (São Paulo: Cosac Naify, 2003). 
No autor, estas proposições se equacionam mediante duas tensões epistemológicas. Pela primeira tensão, o dom é visto, ao mesmo tempo, como o terceiro paradigma e o primeiro paradigma, o que coloca a discussão do dom como dispositivo simbólico universal no plano temporal, atravessando o passado e o presente, e, no plano espacial, atravessando diversos territórios linguísticos e culturais paralelos e também as relações entre homem e natureza. Há uma dimensão moral explícita nessa tensão, na medida em que a aceitação do universalismo da dádiva contribui para problematizar as teses que buscam naturalizar o egoísmo utilitarista (mercado) ou as crenças e regras absolutas (estado), e que são apenas constructos culturais historicamente delimitados. Diferentemente, o universalismo do dom valoriza a solidariedade moral coletiva de caráter transcultural e presente, desde sempre, nas instituições primárias, como aquelas familiares, associativas entre outras. Nesse sentido, o universalismo do dom não é apenas uma engenharia teórica, mas uma condição ontológica necessária para os seres viventes construírem comunidades, independentemente do humano e do não humano ${ }^{4}$.

Por conseguinte, o universalismo do dom rompe com os limites analíticos das teorias sociais contemporâneas que se fundam no dualismo metodológico: sociedade, de um lado, indivíduo, de outro. Este dualismo separa tecnicamente uma realidade que na sua essência é uma unidade, pois o sujeito não está fora do objeto, sendo ele mesmo um objeto; o objetivo e o subjetivo não são realidades distintas, constituindo apenas partes de uma mesma consciência coletiva; e a razão não é o oposto das emoções, na medida em que a própria racionalidade se constitui de impressões afetivas e imagéticas que o sujeito constrói sobre o mundo

${ }^{4} \mathrm{O}$ universalismo do dom atualiza, em última instância, a preocupação de Durkheim a respeito de uma moral cívica formada entre o Estado, os grupos sociais e familiares e os indivíduos e que não se prenda à visão negativista da justiça proposta pelo individualismo utilitarista (Durkheim, 1997, p. 100). 
e que interferem no modo de se calcular e se planejar a ação social ${ }^{5}$. O universalismo do dom impõe, logo, uma dialógica entre várias províncias simbólicas e materiais, aparecendo como um dispositivo básico na construção da realidade social.

A reflexão comparativa sobre os fundamentos das alianças nas sociedades tradicionais levou Mauss a sair de uma visão utilitarista das ciências sociais para entender que as pessoas agem por interesse para si, mas não somente: também agem pelo interesse pelo outro (desprendimento) ou por motivos não interessados, como aqueles da obrigação, da liberdade e do prazer. O dom emerge como paradoxo a partir de uma multiplicidade de motivos que influem na formulação de alianças e obrigações coletivas. Para ele, a dádiva é uma racionalidade de caráter transcultural que está presente em todas as culturas, independentemente de serem tradicionais ou modernas (Mauss, 2003). Este universalismo da dádiva coloca uma questão paradoxal: como pode a dádiva se apresentar simultaneamente como diversidade cultural - como rivalidades, como esmolas, como trocas de gentilezas, de solidariedades, entre outras - e como unidade cultural? O universalismo do dom, de fato, deve ser entendido através dos ângulos paradoxais da unidade e da pluralidade cultural. Tal entendimento paradoxal, no entanto, é a condição para se romper com as visões monoculturais e coloniais que reduzem a ação humana a estratégias cognitivas motivadas apenas pelo interesse do controle do outro e para o benefício de si mesmo. O paradoxo da dádiva libera uma perspectiva cultural e dialógica mais generosa, que inclui as dimensões morais, afetivas, estéticas e simbólicas nas relações entre os humanos e entre estes e os não humanos e a própria natureza.

\footnotetext{
${ }^{5} \mathrm{O}$ dualismo metodológico reforça a visão separada da vida social e desvaloriza o aspecto dinâmico e relacional das diversas dimensões da realidade humana. Para Caillé, a dádiva permite superar esse dualismo metodológico ao introduzir o tema do simbolismo como disposição psíquica e dinâmica na organização do mundo (Caillé, 1998).
} 
Pela segunda tensão o dom é entendido, ao mesmo tempo, como um paradigma e um antiparadigma, o que traz para o debate teórico a importância das representações conceituais paradoxais. Esta tensão surge da ampliação da ideia de paradigma nas ciências, que tradicionalmente é influenciada pelo modo como Thomas Kuhn (1975) entendeu as condições de definição do que seja o saber normal e legítimo num certo momento, o que ele pensou, sobretudo, a partir das ciências duras. Para Caillé, no caso das ciências sociais e da filosofia moral, não se pode conceber a presença de um único paradigma dominante, que revele certo tipo de saber normal sobre a sociedade. Nas ciências sociais, diz ele, há sempre o afrontamento de, no mínimo, dois paradigmas, aos quais se opõe um terceiro, o da dádiva, tal qual pontuado anteriormente (Caillé, 2002a, p.12).

Os estudos sobre a dádiva buscam subverter, a partir do diálogo interdisciplinar e de um entendimento ampliado dos fundamentos da vida humana e da vida em geral, as representações cognitivas do que designamos de racionalidade instrumental para focalizar outros entendimentos da vida social e comunitária, outras racionalidades expressivas. Os estudos etnográficos e as análises comparativas de diferentes culturas e modos de construção das experiências de contratos entre pessoas morais, por um lado, e a relação afetiva e simbólica entre os seres humanos e os seres vivos em geral, por outro, sugerem entendimentos mais ecológicos da sociedade humana com impactos sobre as representações da moral e do certo e errado na vida social.

A conclusão que se obtém desta reflexão inicial é que a manifestação do dom/dádiva como programa de ação, como propõe Caillé na sua releitura e aprofundamento da obra de Mauss, não pode ser explicada apenas por categorias da lógica dualista e causalista moderna, que falham justamente por não entender o valor do simbolismo como condição de estruturação dialógica dos relacionamentos sociais, culturais, políticos, ju- 
rídicos e ambientais. A incorporação da linguagem e do simbolismo nas ciências sociais interfere na dinâmica relacional do sujeito em si e com os objetos (visíveis e invisíveis) que circulam e que permitem a existência e reprodução deste sujeito (Tarot, 1999; Caillé, 2002a). Caillé, fiel à descoberta de Mauss, contribui para deslocar o campo teórico para outro lugar de entendimento a partir do qual o sujeito é colocado como um simbolismo geral ou uma energia psíquica genuinamente relacional. Paralelamente, é de se ressaltar que tal deslocamento não pode ser observado somente a partir de uma perspectiva disciplinar isolada, exigindo o pluralismo epistemológico e paradoxal, ou seja, a valorização de um olhar ao mesmo tempo etnológico, sociológico, antropológico, político, linguístico, filosófico e biológico. Se Mauss falava, sobretudo, das pessoas morais coletivas, com Caillé esse entendimento é ampliado para incluir as pessoas morais individuais, o que é necessário para situar a dádiva no interior das ciências sociais e da sociologia, na contemporaneidade.

A seguir, vamos tentar aprofundar essa dinâmica paradoxal do programa de trabalho do dom/dádiva sugerido por Caillé, examinando com mais detalhe os três postulados inicialmente apresentados.

\section{A dádiva é um terceiro paradigma: \\ a crítica aos horizontes das ciências sociais modernas}

A ideia de paradigma, em Caillé, diz respeito a um modo generalizado e mais ou menos inconscientemente compartilhado de questionar a realidade social e histórica e de conceber respostas para estas questões (Caillé, 1998, p. 13). No caso das ciências sociais, o autor sugere que a questão do paradigma sempre deve ser pronunciada no plural, como paradigmas, como já foi lembrado. Pois a organização dos marcos científicos, pelo menos no plano do social, está conectada aos valores básicos 
que legitimam os usos das técnicas, dos saberes e das instituições sociais. O tema da crítica aos paradigmas nas ciências sociais já está presente na sua tese de doctorat d'état, publicada com o título Splendeurs et misères des sciences sociales, em 1984. Nessa obra, ele sustenta que a possibilidade de um novo paradigma dependeria de uma tríplice crítica: do utilitarismo, do evolucionismo e do racionalismo (Caillé, 1986).

Nesse momento, o autor ainda não tinha explorado a fundo a perspectiva da dádiva como este novo paradigma possível. Os avanços mais claros nessa direção vamos encontrar em Critique de la raison utilitaire, de 1989, quando busca articular as ideias de democracia e comunidade com aquela de dádiva. Aqui, ele propõe que somente pode haver vínculo democrático entre aqueles que partilham o sentimento de formar uma comunidade e que, por consequência, "são capazes de desenvolver virtudes cívicas sem as quais a democracia naufraga necessariamente" (Caillé, 1989, p. 106). Esta pista de análise se amplia com o livro que escreveu em colaboração com Jacques Godbout, intitulado L'esprit du don (Godbout; Caillé, 1992), no qual sistematizam o debate teórico, propondo que a dádiva é um sistema que existe ao lado daqueles do estado e do mercado, estando presente em todos os lugares, inclusive nas sociedades contemporâneas.

Para o autor, os dois paradigmas dominantes na modernidade, o individualista e o holista, oferecem grandes problemas para a explicação da complexidade da vida social. O primeiro é limitado, porque reduz o homem sociológico à ideia do homo economicus, buscando remeter o conjunto dos fenômenos sociais exclusivamente às decisões egoístas e cálculos dos indivíduos (Caillé, 2002a, p.15; 2005). A presença desse paradigma nas ciências sociais se faz por teorias, como a da escolha racional, a teoria dos jogos, a do novo institucionalismo, a do convencionalismo, entre outras. As limitações do segundo paradigma, o holista, se revelam pelo exagero de tentar explicar todas as ações, individuais ou coletivas, 
como manifestação de uma totalidade social que preexistiria aos indivíduos (op. cit., p. 17). Aqui, o autor explica de que modo certas teses, como as do funcionalismo, do culturalismo, do institucionalismo e do estruturalismo, dissolvem o valor da liberdade do sujeito social na constituição das alianças. A dádiva emerge como terceiro paradigma ao recusar os reducionismos anteriores:

A totalidade social não preexiste aos indivíduos como tampouco o inverso, pela simples razão que tanto uns como os outros, como a sua posição respectiva se geram incessantemente pelo conjunto das inter-relações e das interdependências que os ligam. (Caillé, 2002a, p.18)

A formulação do dom/dádiva como um terceiro paradigma contribui, sobretudo, para Caillé aprofundar a crítica do utilitarismo econômico individualista que se tornou o paradigma hegemônico nas sociedades ocidentais, sobretudo após a queda do Muro de Berlim, em 1989. A dádiva, diz ele, extrapola visões reducionistas da vida social como aquela do individualismo liberal - hegemônica com o neoliberalismo - que exalta a superioridade dos interesses individuais sobre aqueles da sociedade. $\mathrm{Na}$ sua crítica, o autor demonstra que esta visão atomista sugere um entendimento fragmentado do ser humano, valorizando o egoísmo de cada um, sem explicar os fundamentos morais legítimos do surgimento das solidariedades coletivas. A visão atomista do indivíduo é simplificada e não dá conta da complexidade de redes e emaranhados que constituem a vida social e que produzem obrigações morais e contratuais necessárias à reprodução do conjunto da sociedade.

Num primeiro plano, observa-se que os estudos sobre a dádiva se aproximam das perspectivas antiutilitaristas de clássicos como Karl Marx, Max Weber e Émile Durkheim, que vêm sendo aprofundados por autores modernos como Norbert Elias (1991), Pierre Bourdieu (1998), Anthony Giddens (2003) e, mais recentemente, aqueles que estão estruturando as 
teorias das redes sociais (Mercklé, 2004), para construir argumentos que permitam superar o dilema teórico tradicional entre sociedade e indivíduo. Num segundo plano, percebe-se que os estudos sobre a dádiva se aproximam de autores que se preocupam mais diretamente com a observação da circulação da ação e com as categorias simbólicas aí presentes, como são os casos de Georg Simmel (2002) e suas categorias da experiência humana e com o interacionismo simbólico (Goffman, 1974; Blumer, 1984). Num terceiro plano, é de se observar que a originalidade dos estudos sobre a dádiva deve-se, em grande parte, a suas fontes empíricas, em particular aos estudos etnológicos que permitiram ampliar o entendimento da natureza social e comunitária para abranger a compreensão das relações humanas propriamente ditas, e das relações da vida em geral. Nessa perspectiva, o dom e o símbolo são vistos como coextensivos, o que permite entender a realidade social como intrinsecamente simbólica (Caillé, 2002a, p. 21).

Os estudos sobre o dom/dádiva oferecem amplas possibilidades de revisão do projeto das ciências sociais, ao demonstrar que o modo dicotômico como a sociedade é representada pelas sociologias modernas empobrece o entendimento da natureza dinâmica das relações inter-humanas. Então, a dádiva aparece como um terceiro paradigma que não é nem holista - voltado para um entendimento da realidade como uma totalidade objetivada - nem individualista - limitado por uma visão atomista dessa mesma realidade. Esse entendimento da dádiva como um sistema de interpretação de outro nível fica mais claro quando consideramos que as teorias holistas e individualistas se fundam numa matriz espacial e temporal estática da realidade: ou se visualiza a sociedade como um conjunto sistêmico objetivado, ou se visualiza a realidade como um conjunto atomizado e igualmente objetivado. A dádiva, ao contrário, funda-se numa matriz espacial e temporal que foca a dinâmica e a fluidez da realidade. 
Podemos usar como exemplo a diferença entre o registro da realidade por uma máquina fotográfica ou por uma filmadora. A fotografia é importante para fixar as imagens, mas não permite visualizar sua sequência; o filme diminui a intensidade do momento fixado mas abre o entendimento da narrativa para uma sequência variada no tempo e no espaço.

A ruptura da limitação da lógica fotográfica dos paradigmas tradicionais somente é alcançada quando se entende a dádiva como um dispositivo de reciprocidade, que envolve diferentes formas de organização das relações entre os seres humanos. No mundo do capital e do trabalho, mas, igualmente, no mundo da vida em geral: das comunidades, das tribos e também dos não humanos. A tese maussiana do fato social total, que sustenta o entendimento da dádiva como sistema dinâmico, constitui uma inflexão com relação ao pensamento de seu tio, Durkheim, que não conseguiu superar a dualidade entre o objetivo e o subjetivo (Caillé, 1998, p. 8). No sistema da dádiva, a vida social aparece como sistema flutuante no tempo, que pode ser observado pela circulação dos bens materiais e imateriais, fertilizados por um simbolismo geral que significa a realidade em cada momento e em cada lugar.

Privilegiando o conceito de símbolo, em lugar daquele de representação, Mauss conseguiu superar os limites de uma lógica causal por outra expressiva na compreensão dos fatos sociais (Karsenti, 1994, p. 86). Nessa direção, a compreensão expressiva da realidade não se faz somente entre o indivíduo e a sociedade (o que induz a uma representação antagônica), mas na própria produção imaginária dessas categorias sociológicas, como processos que expressam planos paralelos da realidade. Daí que a ideia de tradução aparece como dispositivo metodológico central para fazer fluir os diversos planos ou províncias da realidade na organização das solidariedades coletivas, sendo o símbolo nada mais que uma operação de tradução (op. cit., p. 87). A tradução libera o entendimento político 
da linguagem e, sobretudo, das palavras, levando a que se pergunte, em cada momento de uma doação ou recepção de algum objeto ou de um sentimento, o que de fato se pretende com esta palavra dada e recebida (Caillé, 2002b).

O conceito de fato social total permite ultrapassar a materialidade imediata do social para revelar um simbolismo geral da vida, do que entendemos como objetivo e subjetivo, oferecendo uma visão de síntese dos variados e complexos fenômenos humanos e socioambientais. Como esclarece Caillé, no paradigma do dom, a totalidade social não preexiste ao indivíduo e vice-versa, pois ambos são mutuamente transcendentes, e, nesta transcendência, o dom se revela como um fenômeno paradoxal por ser, ao mesmo tempo, obrigatório e livre, interessado e desinteressado (Caillé, 2002a, p. 61).

As representações bipolares da realidade social, dominantes nas ciências sociais, não são arbitrárias, diga-se de passagem, revelando o esforço de objetivação do conhecimento científico, seguindo os rastros sugeridos pelo dualismo cartesiano e pelo esforço de legitimação empírica das ciências sociais no campo científico. O problema é que a comunidade da linguagem e das palavras exige, sempre, um conhecimento reflexivo da prática que escapa dos modelos formais (Freitag, 1985), o qual remete necessariamente para o relacional. A designação do dom como terceiro paradigma ressalta este entendimento relacional, o qual somente se torna consciente quando se entende a realidade social como expressão da sociedade como fato social total, como um simbolismo generalizado que não se enquadra nas visões instrumentalistas dominantes. O fato é que a representação metodológica dualista e instrumental dos sistemas vivos impede entender os dispositivos simbólicos e ritualísticos que dão sentido às manifestações dos indivíduos humanos no ordenamento dos bens materiais e imateriais que circulam em favor do pacto social. Por isso, para 
Caillé, o resgate do simbólico aparece como fundamental para revisitar Mauss e para se fazer justiça a seu lugar como um dos grandes nomes do pensamento sociológico contemporâneo (Caillé, 2002a, p. 19).

\section{A dádiva como paradigma primordial: revisitando o universalismo a partir do pluralismo epistemológico}

A ideia de dom/dádiva como paradigma primordial e primeiro (historicamente anterior aos dois outros paradigmas) surge no momento em que Mauss constata haver em todas as sociedades tradicionais - e modernas - uma obrigação contratual coletiva e costumeira que envolve todas as pessoas morais presentes no ato de fundação do pacto social, a começar pelos grupos primários. A partir dessa evidência histórica e etnográfica, conclui-se que as especulações teóricas atuais sobre o valor primacial das estratégias e crenças dos agentes na formulação da ação social são variadas e delimitadas culturalmente, pois dependem do modo como se institui imaginariamente a sociedade. Mauss (2003) entendeu que as lógicas de ação se inspiram em constructos morais que são relativos - mas sem serem arbitrários - na medida em que eles participam de um sistema de valorização multidimensional, o da dádiva, presente em todas as sociedades. Daí, conclui-se que esta existe em todas as sociedades já inventadas, ordenando os contratos comunitários e sociais. O caráter multidimensional e multidisciplinar da dádiva sugere reflexões importantes sobre os desafios de se repensar a teoria social a partir de uma esfera mais ampla, relacionada com as teorias explicativas da vida em geral, humana e não humana. Nessa perspectiva, entende-se as razões de se propor a dádiva como sendo, de fato e de direito, o paradigma primordial nas sociedades modernas e tradicionais. 
A dádiva é, então, uma teoria e uma prática. É uma teoria, quando aparece como um mapa abrangente para explicar a natureza comum dos seres vivos e dos seres humanos, a qual se realiza pela dinâmica relacional no interior das espécies e entre as espécies. Mas o dom é uma prática, quando se revela como linguagem, como o dispositivo de tradução simbólica que articula diferentes processos de construção social e ambiental da realidade. Como prática, ela é um risco político, na medida em que nada obriga os agentes a se implicarem na formulação de alianças e contratos solidários. Há uma liberdade implícita na escolha entre fazer a guerra ou a paz e que impacta necessariamente nos modos como os seres humanos organizam suas instituições imaginárias do social. Nada obriga a manifestação da aliança do dom; nada obriga que ela não possa se manifestar.

A dádiva fornece as bases de uma teoria das motivações morais complexas do ser humano, que Caillé denomina de uma teoria multidimensional da ação (Caillé, 2002a, p. 126). Há, aqui, lembra ele, quatro incondicionalidades condicionais que emergem como pares: um desses pares sugere que à obrigação de fazer - seguindo crenças, regras e convenções -, se opõe a liberdade individual e coletiva de decidir entre querer ou não fazer; o outro enuncia que ao interesse de fazer algo com vistas a ganhos materiais ou de poder se opõe o desinteressamento, aquele agir realizado por mero desprendimento, em razão do desejo espontâneo de fazer pelo outro, de doar amor à vida ou ao outro (Caillé, 2006). A partir dos entendimentos sugeridos pela dádiva, fica claro que o ser humano não age apenas pensando em si mesmo e nos seus interesses mesquinhos, mas também age pensando nos outros: muitas vezes gratuitamente, outras, por mera obrigação fundada nas crenças ou em convenções. Aliás, a favor da obrigação de generosidade contida na dádiva, não custa lembrar 
que a própria ideia de humano, que vem do grego húmus, que significa fertilizante, tem uma inspiração sentimental coletiva ${ }^{6}$.

Na perspectiva do dom, nem a sociedade nem os indivíduos existem antes do movimento de circulação dos bens, que são a priori intangíveis, pelo menos na sua expressão cultural. Apenas a circulação contínua dos sentidos, significados, imagens e sentimentos permite dar tangibilidade aos bens, determinando tanto os formatos culturais, políticos, morais, psicológicos, sentimentais e estéticos da vida social como a emergência dos agentes e instituições que constituem. As informações que circulam no interior de uma dada comunidade por imagens, gestos, palavras, ritos e crenças compartilhadas, antes de serem reflexos das condutas das pessoas morais, são sistemas de signos e de símbolos que instituem necessariamente os lugares e os comportamentos coletivos e individuais. A totalidade se faz e se desfaz, nesta dinâmica de energia psíquica em circulação, e através dela flui a sociedade em processo de eterna individualização, que é diferente do mero individualismo ${ }^{7}$.

A dádiva nos ensina que as informações circulando nas formas de bens materiais e imateriais e de serviços em favor da instauração do pacto social e comunitário são recicladas por ritos de entrada e de saída, de reconhecimento e de exclusão, levando tanto a dinâmicas comunitárias intensas como a processos de fragmentação das estruturas coletivas e indi-

\footnotetext{
${ }^{6}$ Certamente, no sistema capitalista, o individualismo é um constructo imaginário real pois a sociedade de consumidores estimula a formação de indivíduos egoístas. Mas esse próprio individualismo não emerge do nada, mas, sim, de uma sociedade concreta, cujos sistemas de direitos e valores culturais comporta a atomização da vida social. Se esta sociedade não comportasse a valorização do individualismo, os indivíduos seriam simplesmente expulsos, como nos demonstram vários estudos etnológicos das sociedades comunitárias tradicionais. Caillé lembra, inclusive, que tal atomização tem levado a uma fragmentação importante das instituições sociais e políticas que ele chama de parcelitarismo da democracia (Caillé, 2008).

${ }^{7} \mathrm{~A}$ individualização resulta da crescente complexidade do sistema social, o individualismo é uma leitura ideológica da sociedade a partir de um equivocado entendimento sobre a autonomia das partes do social. O risco, como lembrado, é passar da individualização para a parcelitização, o que compromete as perspectivas da vida democrática (Caillé, 2008).
} 
viduais. Cabe ao ser humano em relação decidir pela guerra ou pela paz, pela vida ou pela morte. Mauss chama a atenção para esta dinâmica psíquica, no seu texto sobre o fenômeno da morte em algumas sociedades tradicionais, mais precisamente o fenômeno da Tanatomania que revela os suicídios coletivos (Mauss, 2003, p. 349). Acontece nos casos em que o sujeito que está morrendo não se crê ou não se sabe doente e apenas por causas coletivas precisas julga-se em estado próximo da morte (Mauss, 2003, p. 350). Esclarece Mauss que esse estado acontece num contexto de ruptura de comunhão com as forças sagradas que sustentam o coletivo, sendo a consciência "invadida por ideias e sentimentos que são totalmente de origem coletiva e que não revelam nenhum distúrbio físico" (op. cit., p. 350) .

Para Caillé, estas situações-limite de natureza simbólica entre a vida e a morte se cruzam com aquelas da obrigação e da liberdade, para fundar um dos alicerces de uma teoria antiutilitarista da ação social. No interior desse cruzamento de possibilidades, permanece o registro da reciprocidade; no seu exterior se estende o sem limites (Caillé, 2009, p. 67). O universalismo da dádiva ultrapassa, então, os limites dos paradigmas tradicionais fundados na separação entre homem e natureza, para buscar as conexões diversas, causais e não causais da realidade que conhecemos.

\footnotetext{
${ }^{8}$ Mas não precisamos voltar muito atrás para observar este evento. No Brasil, por exemplo, verifica-se há tempo os suicídios de indígenas das tribos Kaiowá e Guarani, sobretudo envolvendo indivíduos jovens. Mas podemos, também, afirmar que este fenômeno da morte coletiva surge nos dias atuais de modo mais sutil nos sistemas comunitários modernos, nacionais, étnicos ou religiosos. Há expansão do medo coletivo face aos fenômenos da vida e da morte, envolvendo a velhice; a instabilidade existencial gerada pelo consumo ou o receio de perda de meios de sobrevivência induz os indivíduos a viverem coletivamente sentimentos de tristezas profundas, de enfraquecimento do sistema imunológico e desesperanças. Nestes contextos há a valorização dos rituais sacrificiais coletivos materializados pelas escatologias de final de mundo e que são reforçados pelos sistemas religiosos. O sistema sacrificial justifica escatologias que promovem o renascimento, a renovação ou simplesmente a morte da vida social. São muitos os exemplos que podem ser lembrados nos últimos tempos, como a Alemanha nazista, no século XX, o fundamentalismo do estado islâmico ou o nacionalismo norte-americano, no atual momento. Enfim, há toda uma complexidade ritualística na organização e na reprodução da vida social que somente se explica por um entendimento da sociedade como simbolismo geral que antecede, inclusive, as diferentes racionalidades organizadas para gestão da vida coletiva.
} 


\section{A dádiva como antiparadigma: para uma teoria da vida que engloba o social e o natural}

A ideia da dádiva como um paradigma relacional e primordial leva Caillé a propor que ela também tem um caráter antiparadigmático. Para ele, há que se discutir os limites ontológicos da definição da sociedade como paradigma que conhecemos, que é centrado num entendimento antropocêntrico da vida moderna. Para o autor, há que se rever a relação entre vida social e vida natural para incluir, na definição de natureza social humana, o corpo, o meio ambiente e os demais seres vivos. Para ele, os estudos sobre o dom permitem entender esta relação mais complexa da vida humana e da vida em geral. Aqui, ele introduz um diálogo importante das Ciências Sociais com a Filosofia e com a Biologia. A ideia de que a dádiva pode ou não existir no campo da vida social visa salientar que ela existe, primeiramente, como potência de um saber coletivo instituinte ainda não dado, como simbolização subliminar da vida em geral, antes mesmo de sua emergência como instituição do social: a dádiva é, assim, dádiva do que surge, dádiva do próprio surgir (Caillé, 1998, p. 22) ${ }^{9}$.

A dádiva, diferentemente dos paradigmas dominantes - o individualista e o holista -, apoia-se no simbolismo e no relacional, revelando um antiparadigma, um modo diverso de construir o saber coletivo. Contra as suposições de que o paradigma científico funda um saber dominante em um momento histórico, Caillé sugere que, nas ciências sociais, a realidade se apresenta por uma diversidade de lógicas, existindo em paralelo, revelando a impossibilidade de se apreender o real a partir de um único

\footnotetext{
${ }^{9}$ Tal leitura da realidade gera certa inquietação teórica, principalmente se insistirmos sobre a pseudo universalidade do sujeito ocidental, que se apoia filosoficamente em três dimensões de razão: a racionalidade grega, que propõe a superioridade da razão sobre os saberes bárbaros; a racionalidade judaico-cristã, que sugere uma razão transcendental e universal; e, em terceiro lugar, a racionalidade utilitarista e capitalista, que propõe que todo ser humano é egoísta e individualista e que foi objeto de sua crítica teórica ainda nos anos 80 (Caillé, 1986).
} 
prisma intelectual ${ }^{10}$. A dádiva contribui para radicalizar tal diversidade, ao impor a força explicativa do relacional e do simbolismo, abrindo diversas perspectivas de construção coletiva da realidade. Ou seja, o dom não é uma categoria científica dada a priori, mas uma potência vital e intelectiva que tem seus fundamentos na moral coletiva e, principalmente, nos significados e afetos espontâneos que levam os seres vivos a ficarem juntos para sobreviver.

Isso permite supor que, antes de ser uma teoria, ela é um sistema simbólico, uma categoria fenomenal dada a priori e que contém a potência de uma aliança ainda dada e que pode (não) acontecer. Por isso, Caillé lembra que a obra de Mauss representa uma ruptura com relação àquela de seu tio, Émile Durkheim, na medida em que, introduzindo o tema do simbolismo, ele rompe com a visão objetivista da realidade e traz o relacional como aspecto peculiar da experiência real (Caillé, 1998). Sob as lentes da dádiva, o mundo não é apenas objetivo ou subjetivo. Ele é isto e mais que isto, ele é fluxo de intenções, de imagens, de gestos e de ações plenas de significações ritualísticas e que se expressam na circulação de bens materiais e imateriais entre grupos e indivíduos. A invenção do simbolismo entre Durkheim e Mauss, como lembra Camille Tarot (1999), é um acontecimento fundamental para se entender a complexidade da linguagem, o que também permite situar Mauss como um dos fundadores dos estudos semiológicos. Compreender o dom como antiparadigma amplia o entendimento de seu valor paradoxal, rompendo com os esquemas dicotômicos e liberando uma consciência mais integral e complexa da vida social.

Desdobrando a tese de Caillé, podemos sugerir que a dádiva não é somente antiparadigmática mas, também, pré-paradigmática, ou seja, é

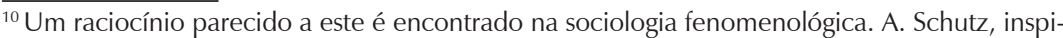
rando-se em W. James, propõe haver diferentes províncias de apreensão da experiência social (Schutz, 1967).
} 
anterior a quaisquer paradigmas, visto que estes são constructos teóricos e de poder que somente surgem a partir de acordos culturais, morais e intelectuais historicamente delimitados. Ao sugerir que a dádiva é também pré-paradigmática, estamos buscando oferecer clareza às reflexões que aproximam o debate sobre a dádiva de teses da biologia relativas à natureza primordial dos seres vivos. Caillé ressalta a tese do biólogo alemão A. Portmann sobre o desenvolvimento do ser vivente como júbilo de autoapresentação. Para este cientista alemão, o desenvolvimento dos seres vivos, humanos e não-humanos, não está apenas condicionado pela função de defesa vital num mundo hostil, como sugere a biologia clássica. Segundo ele, o ser vivente se desenvolve como simbolismo, como impulso primordial de autoapresentação no mundo, como criação singular. Ou seja, a orientação genética e moral dada pelo desejo de liberar a aparência do ser é hierarquicamente superior às necessidades orgânicas e funcionais (Portmann, 1990).

Caillé explora esta tese para propor que "o dom vem, então, a ser dom daquilo que aparece, dom do próprio aparecer" (Caillé, 2002a, p. 78). Ele vê na tese de Portmann uma dimensão antiutilitarista importante na medida em que ela

permite descartar qualquer interpretação utilitarista, funcional ou instrumental do ser vivo, mostrando como este se desenvolve no júbilo da autoapresentação (Selbstdarstellung) e como esta última é hierarquicamente primacial com relação às necessidades orgânicas e funcionais. (Caillé, 2002a, p. 78)

O entendimento da dádiva da autoapresentação é interessante, por sugerir que há no espírito humano uma tendência a sair de si para se relacionar com outros seres (humanos e não humanos), para simbolizar e construir instituições sociais e culturais. 
Caillé faz esta afirmação para reforçar a complexidade do debate científico e as limitações epistemológicas das teorias sociais no interior das ciências do homem. Pois a dádiva não pode emergir materialmente, caso não haja o impulso potencial da sociedade para se autoconstituir como grupo e, no interior deste, como indivíduo, como experiência atômica e social. Não se trata de um processo determinado, mas de movimentos de incertezas ontológicas que somente se revelam como fenômeno visível, caso os indivíduos demonstrem a intenção prática de (não) doar algo a alguém, ou a intenção de (não) receber algo de alguém, ou de (não) retribuir o bem ou favor dado. Se o potencial solidário do dom positivo contido no agir humano não se realiza por aliança voluntária, o dom se transforma em agonismo e, no limite, em violência destrutiva. Onde poderia emergir a paz e a harmonia, nasce a guerra e a desarmonia, a destruição dos pactos, a hostilidade e o ressentimento. Poderíamos dizer que entramos, aqui, no campo de uma antidádiva e, por conseguinte, do anti-humano, do antissocial ou da antivida. Mas, acrescentamos, mesmo que a dádiva como fenômeno social e cultural não aconteça, ela continua a se manifestar como antiparadigma ou como pré-paradigma, através do júbilo incessante dado pela reprodução da vida.

Essa abertura do debate sobre a dádiva para a biologia coloca desafios para explicar a sua ontologia, sugerindo que a energia psíquica que sustenta a vida humana não se limita às representações normais do social oferecidas pelo sistema capitalista, pelas lógicas do trabalho formal e da proteção estatal, devendo incluir necessariamente as tramas da vida comunitária e dos sistemas vivos, em geral. Assim, a dádiva constitui um sistema de pensamento e de ação que não se limita às teorias sociais e culturais modernas, por aparecer como fundamento ontológico dos pactos psicológicos de todas as sociedades existentes, sejam elas modernas ou tradicionais. De certo modo, ela é pré-teórica, na medida em que está 
presente como potência simbólica primordial de interação no imaginário dos seres vivos. Aqui, temos, certamente, uma das explicações possíveis para as dificuldades de situar a dádiva nas teorias das sociedades modernas, pois sua ontologia extrapola os horizontes das ações sociais e culturais contemporâneas para adentrar o mundo do simbolismo e do ritual da vida em geral. Por isso, talvez seja mais interessante entender a dádiva como uma teoria geral da vida.

O interessante nesta revisão ontológica da dádiva como antiparadigmática, isto é, como um sistema teórico que implica o não-agir e o não-existir, são seus impactos para a definição do que seja teoria e do que seja prática.

\section{Dádiva, teoria e prática}

As teorias holistas e individualistas fundam-se numa matriz filosófica problemática, a da filosofia do progresso, que prega uma visão otimista da sociedade industrial e da ideia de desenvolvimento humano e de crescimento econômico. Tal filosofia está intimamente ligada às teses evolucionistas e teleológicas que pregam a libertação do ser humano no tempo futuro. A filosofia do progresso influenciou decisivamente a sociologia moderna, levando os sociólogos a concluírem que suas missões eram as de legisladores de uma realidade positiva, de uma modernização compulsivo-obsessiva que aparentemente reproduzia a modernidade como realidade estável e solidamente enraizada (Bauman, 2010, p. 11). O declínio da modernidade concebida nesses termos ocorreu a partir do reconhecimento filosófico da constatação da ausência de qualquer linha de chegada no futuro promissor imaginado. Para Z. Bauman, a emergência de novas formas de vida, que alguns desenham como pós-modernidade, teria alterado esta percepção com impacto na prática intelectual. Pois, 
se não há linha de chegada, mas somente um fundo de contingências e incertezas, então o intelectual é convidado a se manifestar não apenas como legislador, mas, sobretudo, como intérprete da cultura no mundo globalizado e diversificado no qual ele é protagonista privilegiado (Bauman, op. cit., p. 12).

É importante lembrar que a crítica à ideologia do progresso já vem sendo formulada há várias décadas, principalmente após a Segunda Guerra Mundial. Nesse momento, o pensamento crítico passou a interrogar os sentidos de acontecimentos trágicos como o extermínio de judeus ou as bombas atômicas jogadas no Japão, demonstrando que a realidade histórica era mais um processo em convulsão do que em evolução. Para Maurice Merleau-Ponty, o progresso não é uma necessidade metafísica, mas uma experiência construída pelo homem moderno e com destinos incertos (Merleau-Ponty,1945; 1991). Esta reflexão tem importância crucial para se pensar os limites ontológicos das ciências sociais modernas, que ainda são largamente legitimadas sobre o progresso da modernidade e da modernização do capitalismo. Repensar a relação entre intelectual e cultura, hoje, é fundamental. Já o lembrava Hannah Arendt, ao esclarecer que a condição humana inclui algo mais do que as condições nas quais a vida foi dada ao homem, devendo igualmente considerar as coisas produzidas pela atividade humana (Arendt, 2003, p. 17).

A aplicação desse modelo ideológico do progresso na organização da realidade humana promoveu uma distância metodológica ilusória e relevante entre racionalismo científico e realidade empírica. A representação linear e causal da modernidade demonstrou ser insuficiente para explicar a dinâmica espacial e temporal, paradoxal, multitemporal e multiespacial do processo vital, e que escapa a quaisquer esquemas cognitivos dados previamente pelo Ocidentalismo. Ou seja, há uma distância fenomenal entre a simplicidade do constructo teórico fundado no oti- 
mismo do progresso e adotado pelas ciências sociais modernas, por um lado, e a complexidade da realidade prática, que exige a adoção de um pensamento sistêmico mais amplo e transdisciplinar, por outro (Morin, 1990; Wallerstein, 2006; Caillé, 2009; Martins, 2015a).

Sendo a dádiva antiparadigmática, nela a distância entre teoria e prática se dilui para liberar entendimentos e iniciativas mais dialógicas entre o saber científico e o saber comum, entre a ciência do homem e a ciência da vida. A dádiva é, ao mesmo tempo, o mapa que descreve a realidade e a própria realidade. Se considerarmos que toda teoria constitui um mapeamento da realidade, o que está suposto aqui é que a dádiva é, ao mesmo tempo, a teoria e o processo de mudança da realidade que é objeto de investigação. Nessa ótica, aquele que mapeia a realidade influi sobre o mapa organizado, enquanto a realidade continua a fluir num nível de complexidade fenomenal muito mais ampla do que o mapeador pode imaginar. A questão do simbolismo comunitário faz total diferença para o entendimento da dádiva como sendo, ao mesmo tempo, o mapa da realidade e a realidade mapeada, na medida em que o sujeito-comunidade se realiza enquanto objeto em ação. No caso das teorias holistas e individualistas, que não alcançam o valor da simbolização e da linguagem na construção social da realidade, os mapas interpretativos terminam sendo muito mentais e abstratos. Predominam entendimentos mecânicos e matematizados do mundo, que escondem, sutilmente e inconscientemente, crenças e hábitos ligados às tradições do cristianismo e da filosofia racionalista ocidental.

Por outro lado, ao se pensar a dádiva como um constructo teórico que busca revelar sua própria possibilidade de manifestação, percebemos que ela se apresenta primordialmente como aposta numa aliança incerta, envolvendo seres humanos e natureza não humana. Esta aposta tem um fundamento moral e sentimental importante, por exigir a liberação de 
um valor de confiança no outro, o que significa o risco de dar um passo à frente para que o outro responda espontaneamente (Caillé, 2002a, pp. $54,55)$. Se plantamos sementes, colhemos frutos, se semeamos a destruição, colhemos o caos, independentemente de se falar da comunidade de seres humanos ou do sistema vivo. A dádiva, como pressuposto moral e sentimental de uma prática coletiva fundada na aliança, acompanha, logo, a dinâmica da realidade da vida social, cultural e ecológica, aparecendo como paradigma, quando ação e observação se cruzam numa mesma direção.

No lado inverso, quando desaparecem as condições da aliança, a dádiva vira antidádiva e o sociocultural se desfaz como categoria histórica (Martins, 2006). Nesse caso, a dádiva deixa de ser um paradigma paradoxal na explicação da realidade, sendo absorvida pelas emoções e crenças tumultuadas que desfazem o pacto social e cultural ${ }^{11}$. Nessa linha de reflexão, entendemos que as representações holistas e individualistas que inspiram o sujeito moderno ocidental levam a crescentes dificuldades de se estruturar um pensamento de totalidade intersubjetiva, que considere igualmente os elementos afetivos, psíquicos e morais tanto na organização da ciência como dos processos de poder e de intervenção social. O caráter simplificado do pensamento ocidental tanto reforçou um entendimento eurocêntrico do mundo fundado na superioridade da racionalidade ocidental, como negligenciou as contribuições históricas de culturas não ocidentais. Grande parte dos conflitos geopolíticos internacionais e de gestão do poder nas sociedades nacionais, hoje, deve ser explicada pela ausência de um pensamento mais amplo, ao mesmo tempo teórico e prático, objetivo e subjetivo, como o da dádiva, e que enfatize as condições gerais de organização das alianças entre os seres humanos.

\footnotetext{
${ }^{11} \mathrm{O}$ que observamos atualmente nos antigos estados nacionais da Síria, Iraque, Afeganistão e Líbia, por exemplo, revelam o fenômeno de cessação da dádiva como motor organizador de alianças comunitárias nacionais.
} 
De fato, não se pode reduzir o universo da linguagem e do simbolismo apenas às funções do sistema cognitivo ou da moral ascética que regeram a organização da modernidade ocidental. Certamente, somar, diminuir, multiplicar e dividir são funções centrais para a existência do pensamento lógico, assim como os sentimentos de culpa e de medo que produzem as religiões antropocêntricas também são fundamentais para esta modernidade. Mas devemos, aqui, acompanhar o que nos ensina Cornelius Castoriadis sobre a existência da sociedade como fazer e representar coletivo e anônimo. Ele diz que a instituição imaginária da sociedade é impossível sem uma lógica identitária-conjuntista, que assegure as operações do legein (distinguir-escolher-estabelecer-juntar-contar-dizer). Mas, complementa, é um erro pretender que esta lógica esgote a vida ou mesmo a lógica de uma sociedade (Castoriadis, 1975, p. 266) ${ }^{12}$.

Na perspectiva da dádiva, podemos dizer que a criação humana se dá sempre num contexto cultural particular que define as prioridades e as decisões na organização das alianças. Assim, ao se aprofundar o entendimento da vida social como linguagem e como simbolismo, observamos que as funções cognitivas são modeladas e remodeladas de acordo com prioridades dadas culturalmente, em cada momento histórico. A energia atômica pode servir para a guerra ou para a paz, do mesmo modo que o dinheiro pode ser usado para beneficiar a coletividade ou apenas alguns membros do grupo.

O problema é que a presença de paradigmas simplificados nas ciências sociais como os do holismo e do individualismo, como lembrado por Caillé, ou da agência e estrutura, conforme pensado no mundo anglo-sa-

\footnotetext{
${ }^{12}$ É ingenuidade, alerta ele, não entender que a instituição da sociedade é também e sempre instituição do legein porque ela, a sociedade, é em primeiro lugar uma instituição imaginária e criativa: a instituição da sociedade é instituição de um mundo de significações - que é evidentemente criação como tal e criação a cada vez específica (Castoriadis, 1975: 274). A sociedade se funda, primeiramente, como magma de sentidos, como simbolismo geral, para depois se reproduzir por rotinas mentais que ancoram lógicas explicativas do fazer em sociedade.
} 
xão, contribui para falsear a realidade ao fotografar momentos, perdendo de vista sua fluidez. Enquanto o fotógrafo é empoderado, a realidade é destituída de seu poder simbólico. A limitação do mapa explicativo gera intervenções violentas no real, a partir das organizações estatais e privadas, exaltando emoções individualistas e utilitaristas. Isso provoca ampla desregulação afetiva e emocional do sujeito coletivo e dos indivíduos em geral, como observamos ao refletirmos sobre o estado de falência das instituições sociais e culturais no presente. A colonização da vida planetária se torna colonização da vida cotidiana, impedindo a emancipação de experiências sociais e comunitárias mais saudáveis, fraternas e solidárias, como tem sido lembrado por vários autores pós-coloniais (Lander, 2003; Mignolo, 2007; Santos, 2006; Wallerstein, 2007, Martins, 2015b).

A dádiva constitui, nesse sentido, um terceiro paradigma antiparadigmático e primordial na medida em que convida a se pensar a articulação afetiva da atividade mental crítica com as atividades oníricas, imaginativas e emocionais. Pensar e viver afetivamente ampliam a capacidade de compreensão da realidade para além dos horizontes da colonização planetária, dos sistemas opressores e do individualismo egoísta. Permitem viver o paradoxo não como contradição, mas como liberdade de instituição de realidades humanas multidimensionais e coletivamente gratificantes.

\section{Algumas reflexões complementares sobre a dádiva e as ciências sociais}

A tese sustentada por Caillé sobre a dádiva como sendo, ao mesmo tempo, um terceiro paradigma, um paradigma primordial e um antiparadigma tem relevância para se avançar no trabalho de repensar os destinos das ciências sociais em dois níveis: um deles diz respeito à importância de revisão da fragmentação disciplinar e da importância de um diálogo 
mais amplo no interior das ciências sociais e destas com as demais ciências; o outro se refere à importância de se ampliar as articulações entre os pensamentos eurocêntricos e altercêntricos, deslocando espacialmente e temporalmente os lugares de experimentação, descrição e explicação das realidades múltiplas.

No que diz respeito ao destino das ciências sociais eurocêntricas, que foram hegemônicas na organização do pensamento moderno, observa-se que o declínio da ideologia do progresso histórico tem obrigado a revisões importantes do método científico que M. Merleau-Ponty (1945) realizou pioneiramente, a partir de uma revisão importante do cartesianismo. A crítica antiutilitarista vem buscando aprofundar esta crítica (Freitag, 1985; Caillé, 1986). A tradição do racionalismo científico progressista valorizava exageradamente as técnicas e métodos de apreensão de uma realidade tida como externa, reforçando a percepção errônea da neutralidade científica do observador. Diferentemente, o entendimento do papel do intelectual como intérprete valoriza a relação dialógica entre observação e prática e expande as escutas fenomenológicas e hermenêuticas das múltiplas realidades. O papel do intelectual como intérprete passa a ser valorizado (Bauman, 2010).

No caso específico das ciências sociais, Caillé sugere que as perspectivas de superação da sua fragmentação disciplinar exigem a retomada da dimensão do político. Para ele, as ciências sociais abandonaram, sem se dar conta, a ambição normativa e o sentido político da realidade, comprometendo seu alcance normativo. Segundo ele, reconhecer o político significa resgatar o entendimento do espaço onde se faz a inscrição do conflito e da harmonia, onde se enfrentam os grandes sujeitos coletivos (1993, pp. 40-41). Mas, explica, seria importante para o novo movimento teórico realizar a identificação de um espaço comum à diversas disci- 
plinas em torno de uma ciência social que se apresente como filosofia política e reciprocamente (Caillé, 1993, p.76) ${ }^{13}$.

No que diz respeito à articulação das teses eurocêntricas e altercêntricas, ou entre aquelas do Norte Global e do Sul Global, entendemos que a dádiva contribui para superar esta separação de base colonial. Aqui, Mauss também oferece grande contribuição, na medida em que suas reflexões sobre a dádiva não se inspiram apenas nas sociedades europeias, indo ele buscar exemplos reveladores da dádiva em várias culturas tradicionais e não europeias. Nesse sentido, consideramos que ele realiza uma crítica importante e original para o desenvolvimento dos estudos pós-coloniais, ao valorizar saberes provenientes de culturas não europeias (Martins, 2014) ${ }^{14}$. A contribuição do autor é central para os estudos do Sul Global, na medida em que a ampla revisão etnográfica que realiza na primeira parte do Ensaio... revela seu esforço exitoso de demonstrar que o utilitarismo é uma lógica de ação historicamente delimitada e que pode ser desconstruída criticamente. Diz Mauss: "A própria palavra interesse é recente, de origem técnica contábil: interest em latim, que se escrevia nos livros de contabilidade referindo-se aos rendimentos a receber" (Mauss, 2003, p. 306).

\footnotetext{
${ }^{13}$ Este assunto é bem explorado por outro autor maussiano contemporâneo, Philippe Chanial, quando esclarece que a Sociologia se afirmou, inicialmente, ao romper com as especulações abstratas da filosofia social, mas que, no momento, a saída para uma sociologia fragmentada é reconciliar-se com a Filosofia para aprofundar o entendimento das relações humanas e da sociedade como um todo (Chanial, 2011). A dádiva aparece para os autores como o elo que pode viabilizar tal reconciliação.

${ }^{14}$ De fato, ao se estudar a obra seminal de Mauss, "Ensaio sobre a dádiva..." observa-se que a primeira parte do texto é voltada para a análise dos contratos morais em sociedades não europeias e que a obrigação do dom estaria presente em todas as sociedades tradicionais estudadas. Somente na segunda parte, intitulada de Conclusão, o autor explora as perspectivas do dom para a crítica das sociedades utilitaristas ocidentais, afirmando: "É possível estender estas observações a nossas sociedades.[...] Felizmente, nem tudo ainda é classificado em termos de compra e venda. As coisas possuem ainda um valor sentimental além de seu valor venal, se é que há valores apenas desse gênero" (Mauss, 2003, p. 294).
} 
As perspectivas de surgimento de epistemologias plurais envolvendo diferentes experiências culturais e intelectuais, práticas e teóricas, na produção do saber, é tese igualmente defendida por estudiosos pós-coloniais simpatizantes de abordagens interculturais (Santos; Meneses, 2009; Walsh, 2010) que se aproximam das teses antiutilitaristas europeias. Segundo a crítica pós-colonial, os saberes são sempre contextualizados, mesmo quando podem ser objetos de ampla generalização, como foi o caso da colonialidade do saber promovida pelo capitalismo colonial (Lander, 2003). Nessa perspectiva, na sua conferência no Congresso da Associação Latino-Americana de Sociologia, realizado no Recife, em 2011, Caillé propõe que a sobrevivência da sociologia depende da possibilidade de se abrir para as novas orientações interdisciplinares, como aquelas dos estudos pós-coloniais e dos estudos subalternos, assim como por aquelas de gênero, de cuidado e de reconhecimento (Caillé, 2011, p. 69).

Mauss tem grande importância para o diálogo científico entre campos do Norte e do Sul, quando busca um registro universal como o da dádiva, atravessando diferentes fronteiras culturais. Assim, ele é um pioneiro dos estudos descoloniais (Martins, 2014). Mauss traz na sua abordagem um aspecto crucial para se evitar a generalização do relativismo teórico, ao propor que o dom é o lastro ontológico por excelência sobre o qual se apoiam todas as possibilidades de alianças e saberes. Para ele, apesar da diversidade de situações que a dádiva apresenta ao longo dos tempos, ela se revela sempre como um constructo universal possível, primordial e necessário para o surgimento de alianças entre pessoas morais. Este constructo não está dado a priori, pois ele é anti-paradigmático, é apenas uma possibilidade de generosidade e de solidariedade inscrita na alma humana. Mas a possibilidade de a dádiva se efetivar como aliança é também uma ação política necessária para se organizarem os paradigmas e as instituições. 
Mais recentemente, Caillé vem buscando ampliar as perspectivas do terceiro paradigma como base de um novo movimento teórico pela ideia de convivialismo. Este apareceu, primeiramente, como um manifesto assinado por dezenas de intelectuais renomados e de diferentes países em torno de uma ideia convivialista, que é a aposta na fixação de uma nova filosofia política, de um fundamento durável, ético, econômico, ecológico e político da existência humana e que possa se opor às ameaças entrópicas, materiais, técnicas, econômicas e ecológicas do sistema dominante (Manifeste convivialiste, 2013, pp. 11-15). O convivialismo, esclarece Caillé em texto posterior, busca definir as bases de um bem viver comum, que seja universalizável e no qual possam se reconhecer de modo crescente as associações e redes da sociedade civil e de cidadãos (Caillé, 2015). No nosso entender, o debate sobre o convivialismo encerra, pois, o esforço de potencializar as perspectivas da dádiva como dispositivo de restaurar a relação entre Ciência Social e Filosofia Política e de avançar no diálogo de saberes universais e diferenciados entre os campos científicos do Norte Global e do Sul Global.

Paulo Henrique Martins é professor titular de Sociologia da Universidade Federal de Pernambuco, Brasil. $>$ pahem@terra.com.br. 
Sociologias, Porto Alegre, ano 19, no 44, jan/abr 2017, p. 162-196

\section{Referências}

1. ARENDT, H. A condição humana. 10a․ Ed. Rio de Janeiro: Forense Universitária, 2003.

2. BAUMAN, Z. Legisladores e intérpretes. Rio: Zahar, 2010.

3. BLUMER, H. Symbolic interactionism. Perspective and method. Berkeley/Los Angeles/London: University of California Press, 1984.

4. BOURDIEU, P. O poder simbólico. Rio de Janeiro: Bertrand Brasil,1998.

5. CAILLÉ, A. Le convivialisme en dix questions. Un nouvel imaginaire politique. Paris: Le Bord de L'Eau, 2015.

6. CAILLÉ, A. O estado atual da sociologia: algumas observações face ao próximo congresso ALAS. Estudos de sociologia. Revista do Programa de Pós-Graduação em Sociologia da UFPE, v. 16, n.2, pp.45-55, 2011.

7. CAILLÉ, A. Théorie anti-utilitariste de I'action: fragments d'une sociologie générale. Paris: La Découverte/MAUSS, 2009.

8. CAILLÉ, A. Um totalitarismo democrático? Não, o parcelitarismo. In: MARTINS, P.H.; MATOS, A.; FONTES, B. Limites da democracia. Recife: Editora da UFPE, 2008.

9. CAILLÉ, A. O dom entre o interesse e o desinteressamento. In: MARTINS, P.H.; CAMPOS, R.B.C. (Orgs.) Polifonia do dom. Recife: Editora da UFPE, 2006.

10. CAILLÉ, A. Dé-penser I'économique. Contre le fatalisme. Paris: La Découverte/MAUSS, 2005.

11. CAILLÉ, A. Antropologia do dom: o terceiro paradigma. Petrópolis: Editora Vozes, 2002a.

12. CAILLÉ, A. A dádiva das palavras - o que dizer pretende dar. In: MARTINS, P.H. (Org.) A dádiva entre os modernos. Discussão sobre os fundamentos e as regras do social. Petrópolis: Editora Vozes, pp.99-136, 2002b.

13. CAILLÉ, A. Nem holismo nem individualismo metodológico. Marcel Mauss e o paradigma da dádiva. RBCS, v. 13, n. 38, pp.5-39, 1998.

14. CAILLÉ, A. A demissão dos intelectuais. A crise das ciências sociais e o esquecimento do factor político. Lisboa: Instituto Piaget, 1993.

15. CAILLÉ, A. Critique de la raison utilitaire. Paris: La Découverte, 1989.

16. CAILLÉ, A Splendeurs et misère des sciences sociales. Genève/Paris: Droz, 1986. 
17. CASTORIADIS, C. A instituição imaginária da sociedade. Rio de Janeiro: Editora Paz e Terra, 1975.

18. CHANIAL, P. La sociologie comme philosophie politique et reciproquement. Paris: La Découverte, 2011.

19. DURKHEIM, É. Da divisão do trabalho social. São Paulo: Martins Fontes, 2004.

20. DURKHEIM, É. Leçons de sociologie. Paris: PUF, 1997.

21. ELIAS, N. La société des individus. Paris: Fayart, 1991.

22. FREITAG, M. Ontologie et sciences humaines. Bulletin du MAUSS: Misère des sciences sociales. Paris, 1985.

23. GIDDENS, A. A constituição da sociedade. São Paulo: Martins Fontes, 2003.

24. GODBOUT, J.; CAILlÉ, A. L'esprit du don. Paris: La Découverte, 1992.

25. GOFFMAN, E. Frame analysis. New York: Harper \& Row, 1974.

26. KARSENTI, B. Marcel Mauss. Le fait social total. Paris: PUF, 1994.

27. KUHN, T. A estrutura das revoluções científicas. São Paulo: Perspectiva, 1975.

28. LANDER, E. La colonialidad del saber: Eurocentrismo y ciencias sociales. Buenos Aires: Clacso, 2003.

29. MARTINS, P.H Sistema-mundo, globalizaciones y América Latina. In: BIALAKOWSKY, A.; CHATALIFAUD, M.A.; MARTINS, P.H. (Orgs.) El pensamiento latinoamericano: diálogos en ALAS. Buenos Aires: Teseo, CLACSO/ALAS, 2015a.

30. MARTINS, P.H A descolonialidade da América Latina e a heterotopia de uma comunidade de destino solidária. São Paulo: Anna Blume, 2015b.

31. MARTINS, P.H _O ensaio sobre o dom de Marcel Mauss: um texto pioneiro da crítica decolonial. Sociologias, v. 16, n. 36, pp. 22-41, 2014.

32. MARTINS, P.H.; PESSOA GUERRA, J. de F. Durkheim, Mauss e a atualidade da escola francesa de sociologia. Sociologias, v. 15, n. 34, 2013.

33. MARTINS, P.H. A sociologia de Marcel Mauss. Dádiva, simbolismo e associação. In: MARTINS, P.H.; CAMPOS, R.B.C. (Orgs.) Polifonia do dom. Recife: Editora Universitária da UFPE, 2006.

34. MANIFESTE CONVIVIALISTE Manifeste convivialiste. Déclaration d'interdépendance. Paris: Le Bord de L'Eau, 2013.

35. MAUSS, M. Sociologia e antropologia. São Paulo: Cosac Naify, 2003.

36. MERCKLÉ, P. Sociologie des réseaux sociaux. Paris: La Découverte, 2004. 
Sociologias, Porto Alegre, ano 19, no 44, jan/abr 2017, p. 162-196

37. MERLEAU-PONTY, M. Signos. São Paulo: Martins Fontes, 1991.

38. MERLEAU-PONTY, M. Phénomenologie de la perception. Paris: Gallimard, 1945.

39. MIGNOLO, W. La Idea de América Latina. La herida colonial y la opción decolonial. Barcelona: Gedisa Editorial, 2007.

40. MORIN, E. Introduction à la pensée complexe. Paris: ESF Éditeur, 1990.

41. PORTMANN, A. Essai in Philosophical Zoology by Adolf Portmann: The Living Form and the Seeing Eye. Lewiston/NY: E. Mellen Press, 1990

42. SANTOS, B.S.; MENESES, M.P. Epistemologias do sul. Coimbra: Edições Almeidina, 2009.

43. SANTOS, B.S. A gramática do tempo: para uma nova cultura política. 2ª Edição. São Paulo: Cortez Editora, 2006.

44. SCHUTZ, A. The phenomenology of the social world. Northwestern University Press, 1967.

45. SIMMEL, G. Sobre la individualidad y las formas sociales. Quilmes: Universidad Nacional de Quilmes, 2002.

46. TAROT, C. De Durkheim a Mauss. L'invention du symbolique. Paris: La découverte/MAUSS, 1999.

47. WALLERSTEIN, I. O universalismo europeu. A retórica do poder. São Paulo: Boitempo, 2007.

48. WALLERSTEIN, I. Impensar a ciência social. Os limites dos paradigmas do século XIX. São Paulo: Ideias \& Letras, 2006.

49. WALSH, C. Interculturalidad crítica y educación intercultural. In: VIANA, J; TAPIA, L; WALSH, C.(Orgs.) Construyendo Interculturalidad Crítica. Instituto Internacional de Integración del Convenio Andrés Bello: La Paz, 2010.

Recebido: 27.09.2016

Aceito: 19.10 .2016 